\title{
Estimation of a Health Production Function: Evidence from East-European Countries
}

\author{
Bichaka Fayissa* \\ Middle Tennessee State University \\ Anca Traian ** \\ Middle Tennessee State University
}

\begin{abstract}
The purpose of this study is to estimate a health production function for the 13 East European countries including Belarus, Bulgaria, Croatia, Czech Republic, Estonia, Hungary, Latvia, Lithuania, Poland, Romania, Slovakia, Slovenia and Ukraine. Using panel data from 1997 to 2005 on a diverse array of economic, demographic, environmental, and lifestyles factors as inputs, we analyze a health production function at the macro level in order to determine the most efficient way of allocating limited resources for improving the overall health status of countries in the sample. To control for individual country heterogeneity, we employ panel analytic methods of fixed effects, random effects, and Arellano - Bond estimator. The results indicate that economic growth as measured by GDP per capita growth, investment in human capital formation, and residence in urban areas significantly reduce infant mortality and thus improve the health status of countries in the sample. These findings are useful, not only for serving as background for health care policy decisions, but also for a better understanding of the factors that affect the health condition of the region.
\end{abstract}

Key words: Health Status, Eastern European Countries, Fixed-Effects, Random-Effects, Arellano-Bond estimator

JEL category: I12, I20

\footnotetext{
${ }^{*}$ Corresponding Author: Bichaka Fayissa, Economics and Finance Department, Jennings A. Jones College of Business, Middle Tennessee State University, Box 27, Murfreesboro, TN 37132, e-mail: bfayissa@mtsu.edu ${ }_{* *}^{*}$ Anca Traian, , Economics and Finance Department, Jennings A. Jones College of Business, Middle Tennessee State University, e-mail: traian_a@yahoo.com
} 
1. Introduction

The countries of Eastern Europe have experienced extraordinary changes since the end of 1980's when the socialist regimes were replaced by market-based economies. Many transformations have taken place during the last two decades and sizable improvements can be seen in different areas, but at the same time, these countries continue to face new challenges in the process of their transition to the market economy and their efforts of integration into the western society. Even though Eastern European countries tend to have similar aspirations and problems, one cannot overlook the differences among them in terms of population size (for example, Estonia with a population of 1.3 million and Poland with a population of over 38 million in 2005), level of income, level of development, and other social and economic characteristics.

The health care system is part of the overall reform agenda and this is no surprise considering its importance for the social wellbeing in terms of its contribution to public health capital formation and economic growth. In one of its reports, the Commission on Macroeconomics and Health of the WHO estimates that a "10 percent increase in life expectancy at birth increases economic growth by at least 0.3-0.4 percent of gross domestic product per year" (Suhrcke \& Iliev, 2006). An important point to be noted here is that the changes and improvements of the health care system in the Eastern European countries are ongoing processes. During the communist regime, the health care system was centrally planned and administered; now, a more decentralized system is in place with more private providers and different forms of funding health care services (Rechel \& McKee, 2009). 
Even though important progress has been made, most of the Eastern European countries still have a long way to reach the western countries' health care levels. The life expectancy at birth is rising in all countries at a different pace, but is still below the level of western countries. For example, the lowest levels of life expectancy at birth in the European Union were in Romania (76.2 years) for women and in Lithuania (65.1 years) for men (OECD, 2010). The infant mortality indicator is a mirror image of life expectancy, with higher rates for the newer members. On one side of the spectrum is Luxemburg with the lowest infant mortality rate of 1.8 per 1000 live births while on the other side are Romania and Bulgaria with 11 and 8.6 percent (OECD, 2010). There is no surprise that the lowest level of health care expenditures as a share of gross domestic product is held by an Eastern European country. In 2008, Romania spent 6 percent of its GDP compared to Germany, Austria, Switzerland, and France which allocated more than 10 percent of their GDP (OECD, 2010). The European Union has made efforts to implement policies that will help new members attain, not only the economic status of the veteran states, but also the social, wealth, and national health levels.

Considering the importance of health care for every country in general, and for the Eastern European countries in particular, this paper investigates the impact of the different economic, social, and environmental factors on the health status of member states in the Eastern European bloc. Analyzing the health production function at macro level can offer significant insights for determining the most efficient way of allocating resources for improving the overall health status of countries in the sample. Knowing the degree to which every factor contributes to the improvement of the health status of countries in the sample could help authorities in making decisions and designing more appropriate policies with greater impact. The study is organized as follows. Section 2 provides a brief review of the literature. The model and data are discussed in 
Section 3. The results and interpretations of the study are presented in Section 4.The last section summarizes the findings, draws conclusions, and makes some policy recommendations based on the results.

\section{Literature Review}

This paper is based on Grossman's (1972) seminal work of human capital model of demand for health which posits that health capital increases the market and non-market productive efficiency of an individual. Grossman's initial framework and its extended models help to explain a series of relations such as the health production function, an individual's demand for health, and an individual's health outcomes determined by various exogenous inputs (Schultz, 2004). The importance of the model rests on two aspects: the influence of health on labor productivity and the distinction between the demand for medical services and health (Grossman, 1972; Jacobson, 1999). According to Nixon \& Ulmann (2006), there are two major approaches of explaining the effects of different inputs on health outcomes. First, health is considered to be a commodity and the individual maximizes its consumption subject to a budget constraint and it is also regarded as a capital good having an initial stock which is subject to accumulation and depreciation over time. Second, health represents an output that is determined by different inputs such as health care expenditure, or other medical resources.

Even though there is a rich literature that looks at the relation between the various explanatory variables and health status for many countries and regional economies of Western Europe and North America, there is a dearth of theoretical and empirical research that analyzes the impact of the economic, social, and environmental factors on the health status of EasternEuropean countries using recent data. Studies which measure the conditions of the health capital 
can be of great interest, not only because of the recent integration of most these countries into European Union and their efforts to align them to existing members, but also for each individual country in its attempt to use the limited resources more efficiently. Most of the previous studies use life expectancy at birth, or mortality (age adjusted for infant, or adult) as dependent variables (Auster, 1969; Farrell and Fuchs, 1982; Rosen and Taubman, 1982; Berger and Leigh, 1989). The array of independent variables ranges from health care expenditures and per capita gross domestic product to cigarette or alcohol consumption covering the economic, social, and environmental factors. Furthermore, Nixon and Ulmann (2006) provide a thorough review of the literature with detailed descriptions of existing research related to this paper.

\section{The Model and Data}

This paper follows the footprints of a previous paper "Estimating a health production function for Sub-Saharan Africa" (Fayissa \& Gutema, 2005) which adopts Grossman's (1972) model and transposes it from the micro to the macro level. The health outcome measure (infant mortality rate) is specified as a function of the economic (GDP per capita, health care expenditures, education, food production index), social (marital status, population size, alcohol consumption), and environmental (urbanization, carbon dioxide emissions) factors. Thus, a loglinear Cobb-Douglas production function of the study can be written as:

$$
\ln h=\ln \Omega+\sum \alpha_{i} \ln y_{i}+\sum \beta_{i} \ln s_{i}+\sum \gamma_{i} \ln e_{i}+\mu_{i}
$$

where $\Omega$ is the initial stock of health, $\mathrm{y}_{\mathrm{i}}$ are the economic factors, $\mathrm{s}_{\mathrm{i}}$ are the social factors, $\mathrm{e}_{\mathrm{i}}$ are the environmental factors, and $\mu_{i}$ is the disturbance term. 
The analysis is based on country level data from the World Bank, Eurostat (European Union data bank), United Nations Development Programme (UNDP), and World Health Organization (WHO) for 13 Eastern European countries spanning from 1997 to 2005. Other Eastern European countries such as Moldova and the rest of the former members of Yugoslavia have not been included because of data constraints. Most of the studies use one of the two variables: life expectancy at birth, or mortality rates (age adjusted infant, or adult) as a proxy for health status. According to Nixon \& Ulmann (2006), infant mortality is a better measure because it is more strongly related to the health care system and medical procedures. For the purpose of this paper, infant mortality rate is used as the dependent variable. The data are drawn from Eurostat and they represent the ratio of the number of deaths of children under one year of age per 1000 livebirths during a particular year to the total number of live births in that year. Infant mortality (IMR) can be divided into two components: neonatal and post-neonatal and according to Rowland (1991) is determined by different factors. Prenatal care, education, and nutrition can lower the risk of neonatal mortality while sanitation equipment and medical care affect the postneonatal mortality. A lower IMR can be interpreted as a better health status of the country which can be improved by higher quality of medical and preventive care.

The explanatory variables selected for this paper can be categorized in three subgroups:

- economic factors: gross domestic product (GDP) per capita, total health care expenditure per capita, and food availability;

- social factors: education, adult alcohol consumption per capita, and population;

- environmental factors: urban population and $\mathrm{CO}_{2}$ emission.

The descriptive statistics are presented in Table 1. 
$<<$ Table 1 about here $>>$

GDP per capita is taken from the World Bank's World Development Indicators CD and it is calculated as the gross domestic product divided by midyear population. In order to maintain the uniformity of the data as much as possible, GDP per capita is used in current US\$. The causal relation between income and health is not completely clear since income can influence health through better food, better services, and access to medical care, but better health can also lead to higher income through higher labor productivity, labor supply, or education. On the one side, income has a positive effect on health (Ettner, 1996) while on the other side, health determines economic growth (Bhargava, et al., 2001; Favaro \& Suhrcke, 2006). The existing literature brings up another issue that money can buy better health up to a point, after that threshold is reached, however, it can adversely be affected by increasing income (Fayissa and Gutema, 2005). However, the analysis of the Eastern European countries does not have to address this problem due to the prevalence of poverty and income inequality in these countries. Thus the expected sign of the coefficient of income a priori is ambiguous.

Total health expenditure is the sum of public and private expenditures on health. It is provided by World Bank and includes the provision of health services (preventive and curative), family planning activities, nutrition activities, and emergency aid designated for health, but does not include provision of water and sanitation. According to OECD (2010), the allocation among different health care services varies from one country to another depending on the availability of resources. Furthermore, the allocation of resources within a country is different depending on region. For example, Romania allocated 167 percent of the national health care spending per capita to its capital city, Bucharest to the detriment of other regions (Vladescu et. al, 2000; Reckel \& McKee, 2006). According to the European Communities \& WHO (2002), “total health 
care expenditures as a percentage of gross domestic product is the lowest in Romania, Latvia, and Bulgaria, while Estonia, Poland, Lithuania, Hungary, Slovenia, Slovakia, and the Czech Republic report levels equal to the EU minimum, though below the EU average." The effect of health care expenditures on the health outcome is not clearly defined; it can have a positive effect as long as the health expenses are not made to the detriment of healthy living decisions such as better food or health promoting activities (Fayissa and Gutema, 2005; Nixon \& Ulmann, 2006).

Food production index is used as a proxy for food availability and it is defined by the World Bank as including food crops that are considered edible and that contain nutrients, excluding coffee and tea because they have no nutritive value. While the expected sign is negative, some problems may arise. Low income families may have difficulties in obtaining the essential food even though the food may be available. Mothers may neglect themselves in order to ensure their children receive enough food, resulting in poor nutrition and thus in higher infant mortality at birth. Another consideration is the effect of nutrition on the health status; the European Commission (2007 cited in WHO, 2010) is suggesting that intake of fruit and vegetables is a good indicator of health. Because of lack of data, this aspect could not be included in the paper.

The gross enrollment (primary, secondary, and tertiary) variable is used as a proxy for education. It is the ratio of total enrollment to the population of the age group that officially corresponds to the level of education shown. The data are collected from United Nations Development Programme's Human Development Index (HDI) which is a composite index of the rate of income growth, literacy, and life expectancy. Better education can decrease infant mortality, and thus the sign of the coefficient is expected to be negative. There is strong evidence in the literature that higher education for women leads to better health outcomes in general and in 
children's health status, in particular (Bozicevic, 2006; OECD, 2010). Education has a dual impact on the health status; the direct impact is determined by the health choices such as seeking medical care when needed, or nutritional food intake and the indirect effect is determined by the labor market outcomes (high wages). According to OECD (2010), people who are unemployed over an extended period of time report bad or very bad health status (Baert and de Norre, 2009). In a recent study of Bulgaria, Estonia, Hungary, Poland, and Slovakia, the hypothesis that "persons with higher education are more likely to be in good health" failed to be rejected four out of five times (the exception being Bulgaria for which the result is not available) (Golinowska et al., 2006).

Alcohol consumption per capita is provided by the WHO and is computed as the sum of alcohol production and imports, less alcohol exports, divided by the adult population (aged 15 years or older). Alcohol consumption has been proven to have a great impact on health. The WHO (2010) reports that approximately 25 percent of differences in life expectancy between men, 20 - 64 years old in Western and Eastern Europe can be explained by alcohol consumption. The consumption of alcohol has been associated with increased risks for several diseases and birth defects and it has a negative impact on mortality (OECD, 2010). According to Gilmore et al. (2004), the effect of alcohol on health can be divided in two categories depending on the predominant consumption of spirit or wine. On one side, spirit consumption leads to death from acute intoxication, violence, and sudden cardiac attack while wine is responsible for liver cirrhosis. On the other hand, there are studies that suggest moderate consumption of alcohol may positively contribute to an improvement in health status at the margin by decreasing the risk of heart failure among older persons (Abrhamson et al., 2001) 
Population is the last variable included as a social factor. It is not a determinant of health per se, but it is included in the model in combination with food production index. As explained in Fayissa \& Gutema (2005), food production index is calculated at the aggregate level. Thus, population is included in the model in order to switch from the macro perspective to the micro level. The food availability index has a valid effect on health when it is considered at per capita level, not at national level.

Urbanization rate represents the percent of the population living in urban areas and is made available by World Bank. It has a deep and dual impact on health. First, the access to medical care, the availability of medical resources, and the quality of these resources are considered to be higher in urban areas and thus positively impacting health status. Second, it reflects the stress or the level of pollution that can have a negative consequence on health. Golinowska, Sowa \& Madry (2006) give as an example the lower health status in rural Poland because of the inadequate medical resources, alcohol abuse, or accidents at work. Urbanization will also pick up the inequalities in the distribution of health resources between rural and urban areas. Zaborowski \& Rebandel (2001) argue that75 percent of medical staff is employed in urban areas serving 65 percent of the population (Zajac, 2004). The same problem of uneven distribution of specialists has been observed in many other Eastern European countries where doctors have moved from rural areas to urban areas (Rechel \& McKee, 2006).

The carbon dioxide emission variable is expressed in metric tons per capita and includes the emissions from the burning of fossil fuels and the manufacture of cement. This indicator is also available from World Bank's data bank. The negative health effect of environmental pollution (air, water) on the public health status has been well documented in previous studies, either directly by exposing people to harmful agents, or indirectly by disrupting life-sustaining 
ecosystems (WHO, 2009). We use carbon dioxide emission as a proxy for pollution to capture its negative effect on health. During the communist regimes, the Eastern European countries reached alarming levels of degradation of the natural environment (Jedrychowki, 1995). Even though integration into the European Union has imposed many restrictions intended to control and reduce pollution, these countries still face numerous challenges and higher risks than other members of the EU. For many countries in the sample, the numbers have improved during the study period and they are expected to improve in the future.

4. The Empirical Model and Results

4.1 Pooled regression:, fixed-effects and random-effects models

The paper analyzes 13 Eastern European Countries over a period of 9 years from 1997 to 2005. The model to be estimated is the general form of Equation 1:

$$
h(i t)=\alpha_{0}+\sum \alpha_{i} y_{i t}+\sum \beta_{i} s_{i t}+\sum \gamma_{i} e_{i t}+\epsilon_{i t}
$$

where $\alpha_{0}$ is a constant, $\mathrm{y}_{\mathrm{it}}$ are the economic factors, $\mathrm{s}_{\mathrm{it}}$ are the social factors and $\mathrm{e}_{\mathrm{it}}$ are the environmental factors of the $i$ th country in period $t, \varepsilon_{\mathrm{it}}$ is a disturbance term with $\varepsilon \sim \mathrm{N}\left(0, \sigma_{\varepsilon}^{2}\right)$. For the estimation of the coefficients of the explanatory variables, a panel data analysis is used. Three different approaches for $\alpha_{0}$ are analyzed. The first approach assumes that $\alpha_{0}$ does not vary across countries or time. In this case, the model can be interpreted as a simple OLS regression. The second method specifies $\alpha_{0}$ so that it varies across countries, but remains constant for each country over time ( $\alpha_{0}=\alpha_{\mathrm{i}}$ where $i$ represents the country). This assumption yields the fixed-effect model. The last approach defines $\alpha_{0}$ different for each country, as the previous method, but it also allows $\alpha_{0}$ to vary within each country. In this case, $\alpha_{0}$ is not a point estimate, but rather a disturbance term and can be defined 


$$
\alpha_{i}=\alpha+\omega_{i}
$$

where $\omega \sim \mathrm{N}\left(0, \sigma^{2}{ }_{\omega}\right)$. This time a random effect model is used to estimate the coefficients.

The results for each model are presented in Table 2. In order to choose a reliable model for our analysis, we perform a series of tests. To decide between the first and second approach, the F-test is used to check if there are differences among intercepts $\left(\mathrm{H}_{0}=\right.$ there is no difference). The null hypothesis is rejected at p-value equal to 0.000 . The conclusion is that the pooled regression model (OLS) would not capture the differences between countries. A Lagrange multiplier test is also used to determine the significance of the country specific-effects with the null hypothesis of $\sigma_{\omega}^{2}=0$. We are able to reject the null using a $\chi^{2}$ of 147.41 at a p-value of 0.000 . One more time, the importance of the country specific effects is revealed and the test rejects the suitability of a pooled regression model.

\section{$<$ Table 2 about here $>>$}

The problem that must be addressed at this juncture is the endogeneity between the observables and unobservables i.e. the correlation between the independent variables and $\omega_{i}$ must be equal to 0 ; otherwise, the estimated parameters will be biased and suspect. The Hausman test is the appropriate method for testing for endogeneity with the null hypothesis of no difference in the parameter estimates using the fixed-effects and random-effects models. The null fails to be rejected at 5 percent significance level $\left(\chi^{2}=11.56\right.$; $p$-value $\left.=0.17\right)$, suggesting that the $\omega_{i}$ is not correlated with the observed variables and hence the random-effects model is more appropriate for the interpretation of the results. Analyzing the coefficients generated by the random effects model, there are three variables that have a statistically significant impact on the health status: income per capita, education level, and alcohol consumption. The coefficients of 
the explanatory variables are elasticities since the estimates are based on the log of the variables. The coefficient of GDP per capita of 0.23 is negative and statistically significant, suggesting that a 1 percent increase in the GDP per capita decreases infant mortality rate by about 0.23 percent, other variables remaining unchanged. Taking into account the current trend with respect to GDP that most of the countries doubled if not more than doubled their numbers, it is expected that the infant mortality will continue to decline in the future. Even though this would be the logical trend of thought, an increase in GDP is by no means a guaranty of a reduction in infant mortality.

The proxy for the human capital formation (ENROLLMENT) has a positive and statistically significant effect on health status. Its coefficient value of 0.96 implies that a 1 percent increase in the enrollment ratio will result in a 0.96 percent reduction in the mortality rate. This result suggests that increased investment in education may provide future mothers with the necessary knowledge for a healthy pregnancy and after birth child survivability and it can also indicate better awareness of healthy lifestyle choices, in general. Because infant mortality reflects deaths caused during the first year of life, medical resources in general, and medical staff in particular, have a considerable impact. A higher rate of enrollment may reflect better qualified people (e.g. medical doctors, nurses, technicians) who can provide better health services in the future. The level of education is pretty much homogenous among the Eastern European countries and it is one of the few aspects which has not dramatically changed after the fall of the communist regimes.

The last variable that has a statistically significant impact on mortality is alcohol consumption (ALCOHOL). The estimate shows that a 1 percent increase in the alcohol consumption would lead to a decrease in infant mortality by 0.14 percent. This relation stands against the general belief that alcohol has an adverse effect on health status. An improvement of 
the model is to use the lagged values for alcohol consumption, taking into account the fact that the intake of alcohol does not have an immediate effect on health and it usually is a deferred outcome or consequence. Overall, while it has been established that the negative effect of alcohol consumption outweighs its positive effect, there are some scientific studies which suggest that the association between drinking and mortality during a 20-year period, which controlled for confounding factors such as previous problem drinking, confirms a positive association of moderate drinking and reduced mortality among older adults (Abramson et al.1977). Since we are measuring the alcohol consumption impact on infant mortality, the positive association between infant mortality and alcohol consumption is not plausible.

Other variables, such total health expenditures as percent of GDP and the urbanization rate, have a positive impact on the health status, but the coefficients are not supported by statistical significance. The total health expenditures variable can have biased significance due to correlation with other variables, even though the percent of GDP indicator was used. The food production index and $\mathrm{CO}_{2}$ emissions do not have statistically significant coefficients; also, they do not have the expected sign. As previously explained, the intercept is interpreted as initial stock of health. Because the dependent variable has a negative connotation related to health, it represents the initial stock of "poor health" and it has a statistically significant coefficient. It has no importance when considering the strategies to decrease the infant mortality, thus it is beyond the scope of the paper.

\subsection{Arellano - Bond Estimator}

The concern we have with the previous specification is endogeneity. It is hard to believe that there is a feedback relationship between infant mortality and GDP, but if we consider that 
infant mortality is used as a proxy for health status, the feedback relationship is possible. Health status is affected by GDP and the GDP itself may be affected by the health status. Since low infant mortality could affect the GDP in the future, but not the current value, it is necessary to perform further analysis. To address this issue, we use the Arellano-Bond (1991) estimator. The model is specified as follows:

$$
\Delta y_{i t}=\alpha \Delta y_{i t-1}+\beta \Delta x_{i t}+\Delta \varepsilon_{i t},
$$

where $\Delta \mathrm{y}_{\mathrm{it}}$ is the first difference of the log of infant mortality, $\Delta \mathrm{y}_{\mathrm{it}-1}$ is the lagged first difference the dependent variable, $\Delta \mathrm{x}_{\mathrm{it}}$ is a vector of first differenced explanatory variables and $\Delta \varepsilon_{\mathrm{it}}$ is the first differenced error. The model relies on the assumption that the errors are serially uncorrelated. The explanatory variables can be exogenous, predetermined or endogenous. The exogenous variables are not correlated with the error term, the predetermined variables are correlated with the past values of the error term, but not with the future errors and the endogenous variables are correlated with both past and future errors ${ }^{1}$. In our specification, total health care expenses as a percent of GDP, food production index, urbanization rate, $\mathrm{CO}_{2}$ emission, population, and alcohol are considered exogenous variables, while the GDP and enrolment are considered endogenous. The results are presented in Table 3.

$$
<\text { Table } 3 \text { about here }>>
$$

Comparing Arellano - Bond estimates to random effects results, most of the variables maintain their sign and significance. GDP is statistically significant, having a positive impact on infant mortality. A rise of 1 percent in GDP determines a reduction in infant mortality of 0.21 percent. Enrolment also has a negative and statistically significant effect on infant mortality;

\footnotetext{
${ }^{1}$ A thorough description of the Arellano - Bond estimator can be found in Cameron \& Trivedi (2009).
} 
more education leads to better health related decisions. Contrary to the random effects results, the coefficients for urbanization and $\mathrm{CO}_{2}$ emission are significant while the coefficient for alcohol is no longer statistically significant at $5 \%$ level. Urbanization contributes to the reduction of infant mortality and the effect is not trivial; an increase of 1 percent in urbanization leads to a decrease of 4.25 percent in infant mortality. The effect can be triggered by the better and easier access to medical care and even education. The living conditions in the rural area are worse than those in urban areas for most of the Eastern European countries and many villages do not have medical assistance available. The $\mathrm{CO}_{2}$ emission variable that represents the damaging effects of the environment causes, as expected, an increase in infant mortality. The coefficients for total health care expenses as percent of GDP and Food Production Index are not statistically significant. Similar results were obtained using the random-effects model.

\section{Conclusions}

Using the theory developed by Grossman (1972), the framework provided by Fayissa \& Gutema (2005) and panel data for 13 of the countries in the Eastern European Bloc over a period of 9 years (1997 to 2005) drawn from several international sources, the study analyzes the impact of economic, social, and environmental factors on the health status of countries in the sample. The results indicate that economic growth as measured by GDP per capita growth, investment in human capital formation, and residence in urban areas significantly reduce infant mortality and thus improve the health status of Eastern European countries. The findings may serve as a starting point in developing a health policy that is directed toward improving the health status of the Eastern European region to the level of Western European countries. 
The paper acknowledges that these countries have different histories, backgrounds, resources or sizes and uses different models capable of including these dissimilarities. The results suggest that policies that promote an increase in the gross domestic product will result in the reduction of infant mortality. The current upward trend in GDP promises bright prospects in the improvement of the health status of the region in general, and infant mortality, in particular. The results also suggest that education plays a key role in improving public health. Education can provide the necessary knowledge to make wise decisions about things that affect health. The study also reveals that urbanization rate and pollution (represented by the $\mathrm{CO}_{2}$ emission) should not be ignored by the policy makers; both factors can lead to better health. Urbanization enables the access to medical care and a higher living standard, while a reduction in pollution can diminish the risk for different illnesses.

To make a policy recommendation based on a reduced form evidence may be a precarious proposition; nevertheless, a good strategy for the Eastern European countries is to focus part of their limited resources on economic growth promoting goals, especially education. A nice extension of the model would be to use gross enrollment by gender in order to capture the proportional difference in the health status improvement based on education by gender, but the major impediment is data availability. 


\section{References}

Abramson, Setareh Williams, Krumholz, Harlan \& Vaccarino, Viola. 1977. Moderate alcohol consumption and risk of heart failure among older persons. Journal of American Medical Association, 303 (15): 1490-1497.

Arellano, Manuel \& Bond, Stephen. 1991. Some tests of specification for panel data: Monte Carlo evidence and an application to employment equations. Review of Economic Studies, 58: 277-297.

Auster, Richard, Levenson, Irving \& Deborah Sarachek. 1969. The Production of Health, an Exploratory Study. Journal of Human Resources, 4: 411-436.

Baert, Katrien \& De Norre, Bart. 2009. Perception of health and access to health care in the EU25 in 2007. Eurostat Statistics in Focus, 24: 1-12.

Berger, Mark \& Leigh, Paul. 1989. Schooling, self-selection, and health. Journal of Human Resources, 24: 433-455.

Bhargava, Aloc. Jamison, Dean \& Murray, Christopher. 2001. Modeling the effects of health on economic growth. Journal of Health Economics, 20: 423-440.

Bozicevic, Ivana. 2006. Health and economic development in South-Eastern Europe. Paris: WHO Regional Office for Europe.

Cameron, Colin \& Trivedi, Pravin. 2009. Microeconometrics using Stata. College Station: Stata Press.

Ettner, Susan. 1996. New evidence on the relationship between income and health. Journal of Health Economics, 15: 67-85.

European Commission. 2007. White paper on a strategy for Europe on nutrition overweight and obesity related health issues. Brussels: Commission of European Communities.

European Communities and World Health Organization. 2002. Health status overview for countries of Central and Eastern Europe that are candidates for accession to the European Union. Copenhagen: WHO Regional Office for Europe. 
Favaro, Donata \& Suhrcke, Marc. 2006. Health and economic development in South-Eastern Europe. Paris: WHO Regional Office for Europe.

Fayissa, Bichaka \& Gutema, Paulos. 2005. Estimating a health production function for SubSaharan Africa. Applied Economics, 37: 155-164.

Gilmore, Anna B., Esa Osterberg, Antero Heloma, Wiltold Zatonski, Evgenia Delcheva, Martin McKee. 2004. Health policy and European Union enlargement - Free Trade versus the Protection of Health: The Examples of Alcohol and Tobacco. In: Mckee Martin, Maclehose Laura, Nolte Ellen., editors New York: Open University Press.

Golinowska, Stanislawa. Sowa, Agnieszka \& Madry, Roman. Health status and health care systems in Central \& Eastern European countries. Brussels: European Network of Economic Policy Research Institute.

Grossman, Michael. 1972. The demand for health: A theoretical and Empirical Investigation. New York: NBER.

Iliev, Dimo \& Suhrcke, Marc. 2006. Health and economic development in South-Eastern Europe. Paris: WHO Regional Office for Europe.

Ivana, Bozicevic. 2006. Health and economic development in South-Eastern Europe. Paris: WHO Regional Office for Europe.

Jacobson, Lena. 1999. The family as producer of health - an extended Grossman model. Journal of Health Economics, 19: 611-637.

Jedrychowski, Wieslaw. 1995. Review of recent studies from Central and Eastern Europe associating respiratory health effects with high levels of exposure to "traditional" air pollutants. Environmental Health Perspectives, 103(2): 15-21.

Nixon, John \& Ulmann, Philippe. The relationship between health care expenditures and health outcomes. European Journal of Health Economics 7: 7-18.

OECD. 2010. Health at a glance: Europe 2010. OECD Publishing. 
Public Health in Central \& Eastern Europe the Role EU pollution http://academic.research.microsoft.com/Paper/10603679.aspx

Rechel, Bernd \& Mckee, Martin. 2006. Health and economic development in South-Eastern Europe. Paris: WHO Regional Office for Europe.

Rechel, Bernd \& Mckee, Martin. 2009. Health reform in central and eastern Europe and the former Soviet Union. Lancet, 374: 1186-1195.

Remoundou, Kyriaki \& Koundouri, Phoebe. 2009. Environmental effects on public health: An economic perspective. International Journal of Environmental Research and Public Health, 6(8): 2160-2178.

Rosen, Sherwin \& Taubman, Paul. 1982. Some socioeconomic determinants of mortality Economics of Health Care. New York: J. Van der Gagg, W. B. Neeman, and T. Tsukahara, Preager Publishers.

Rowland, Diane. 1991. Health status in East European countries. Health Affairs, 10(3):202-215.

Schultz, Paul. 2004. Health Economics and applications in developing countries. Journal of Health Economics, 23: 637-641.

Vladescu, Cristian et al. 2000. Health care systems in transition: Romania. Copenhagen, European Observatory on Health Care Systems.

Zaborowski, Piotr \& Rebandel, Henryk. 2001. The profession of physician in Poland: Demographic analysis approach. Gazeta Lekarska, 4.

World Bank. 2000. World Development Report 2000/2001: Attacking Poverty. Oxford University Press, New York.

World Health Organization (WHO). 2009. Preventing disease through healthy environments: Towards an estimate of the environmental burden of disease. International Journal of Environmental Research and Public Health, 6(8): 2160-2178.

World Health Organization (WHO). 2010. European status report on alcohol and health 2010. Copenhagen: WHO Regional Office for Europe. 
Zajac, Monika. 2004. Health policy and European Union enlargement - Free movement of health professionals: The Polish experience. New York: Open University Press. 

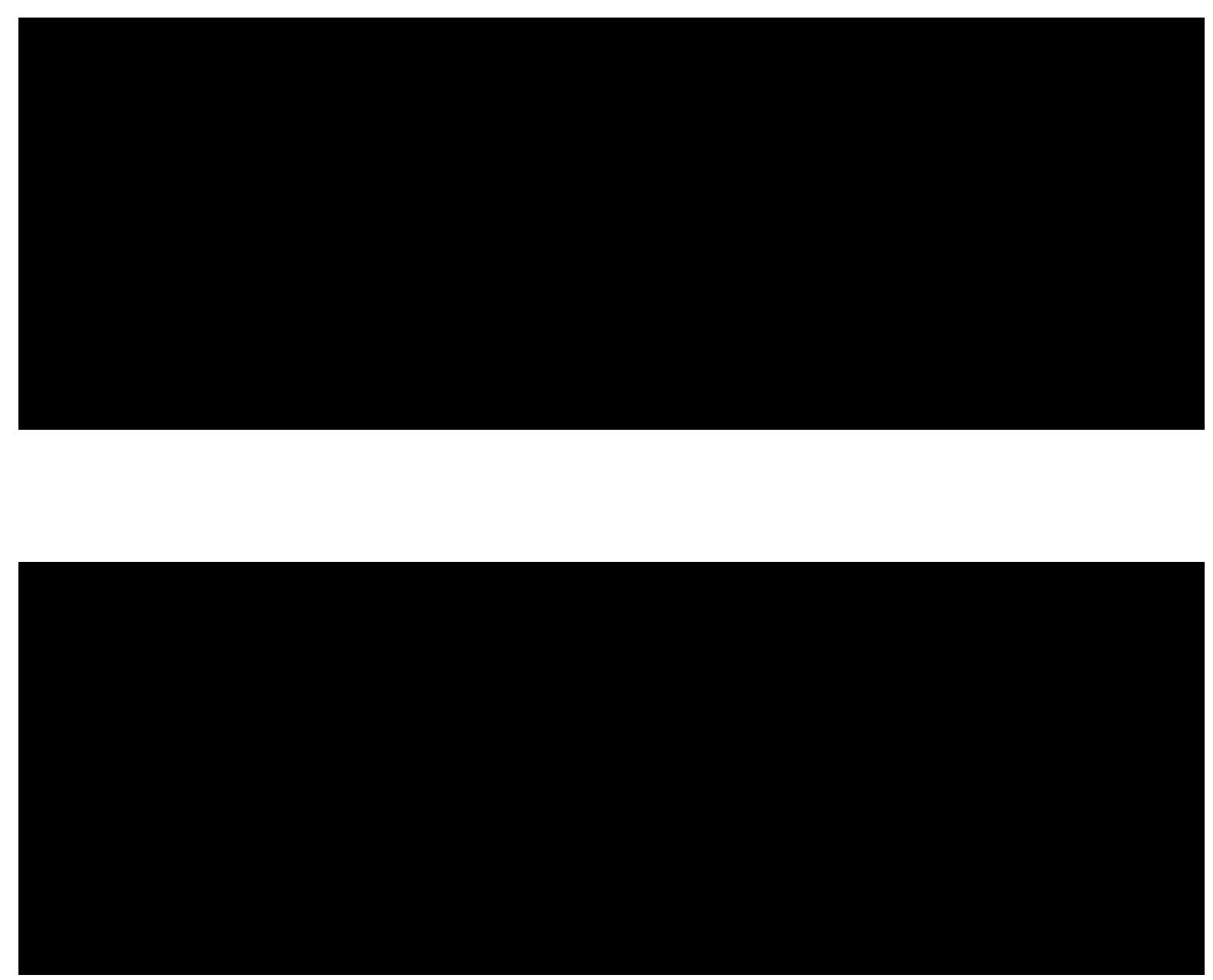


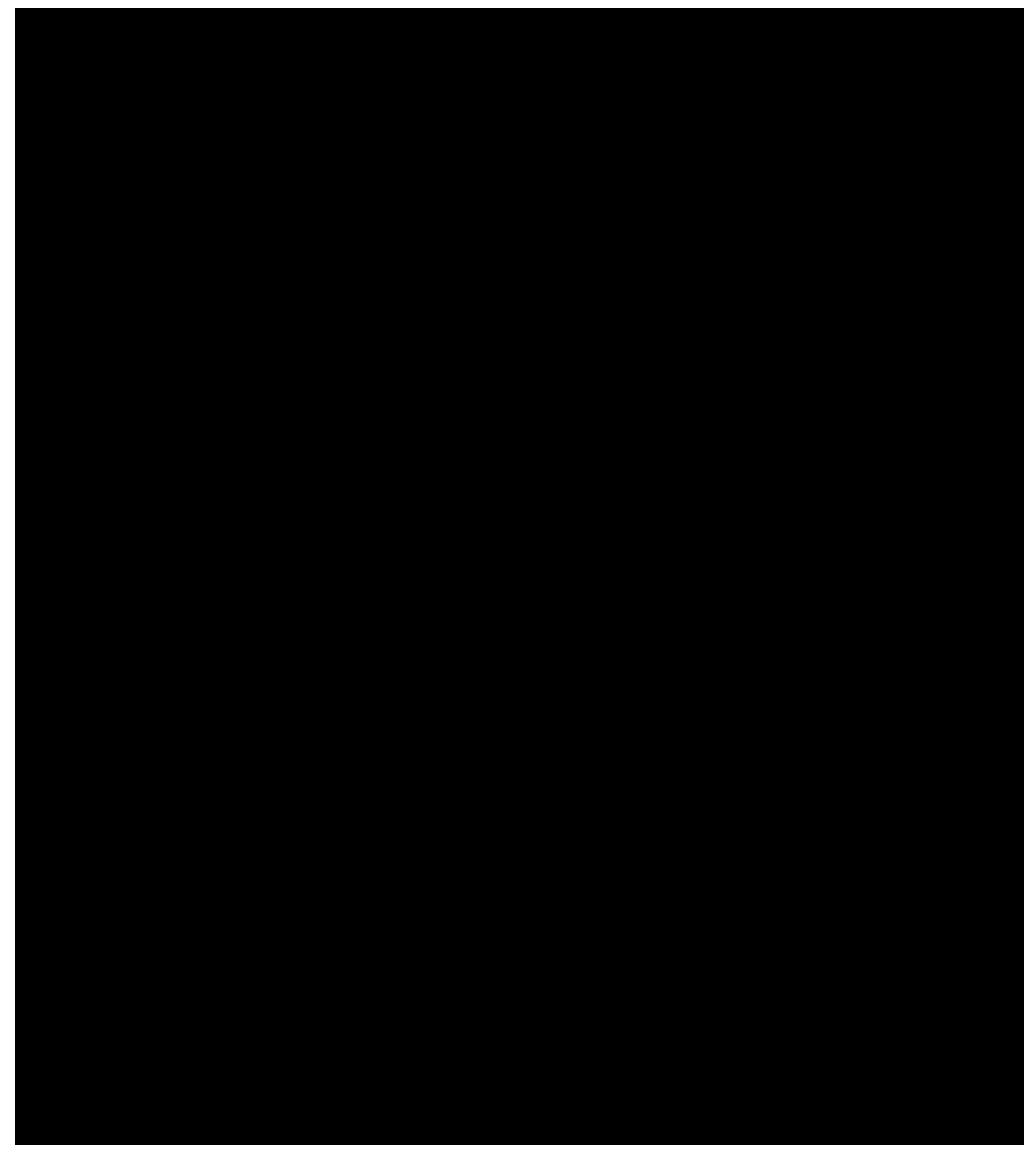



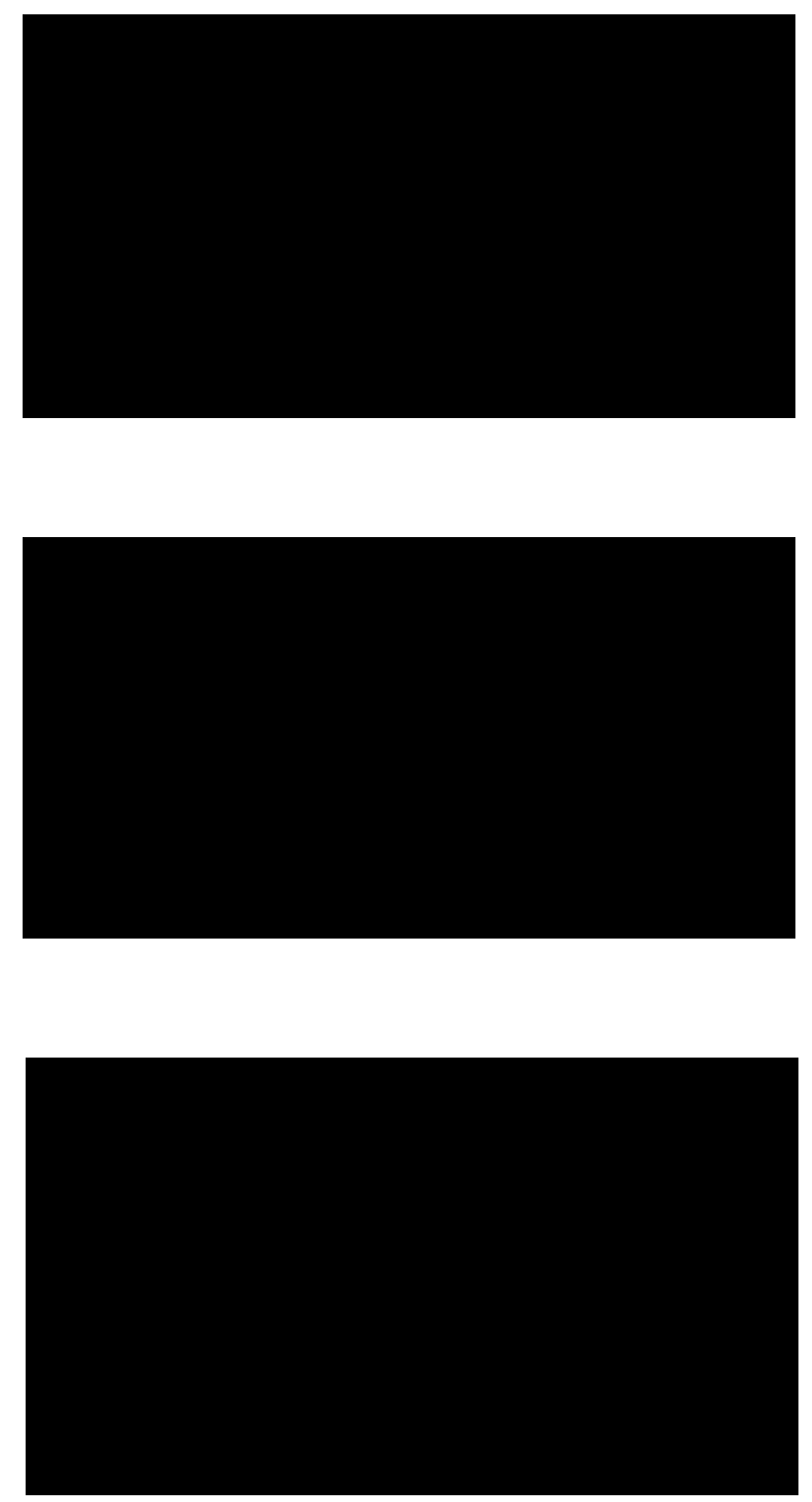
Table 3: Arellano - Bond Estimator

\begin{tabular}{lcccc}
\hline & Coefficients & Std. Err. & z-value & $P>|z|$ \\
\hline Infant Mortality L1 & 0.132 & 0.127 & 1.030 & 0.302 \\
GDP/P & -0.213 & 0.058 & -3.700 & 0.000 \\
THE\%GDP & -0.027 & 0.161 & -0.170 & 0.869 \\
FPI & 0.030 & 0.101 & 0.300 & 0.765 \\
ENROLLMENT & -0.661 & 0.241 & -2.740 & 0.006 \\
ALCOHOL & -0.162 & 0.089 & -1.810 & 0.070 \\
POPULATION & -0.769 & 1.373 & -0.560 & 0.576 \\
URBAN & -4.250 & 1.767 & -2.400 & 0.016 \\
CO2 & 0.504 & 0.185 & 2.720 & 0.007 \\
CONST. & 35.647 & 28.431 & 1.250 & 0.210 \\
\hline
\end{tabular}

Notes: Instruments used for GDP are GDP(t-2), GDP(t-3), GDP(t-4)

Instruments used for Enrollment are Enrollment(t-2), Enrollment(t-3), Enrollment(t-4) Instrument used for Infant Mortality is Infant Mortality (t-2)

Test for no autocorrelation in first differenced errors:

$A R(1): z=-2.44$ Prob $>z=0.015$

$\operatorname{AR}(2): z=1.43$ Prob $>z=0.154$

$A R(3): z=0.820$ Prob $>z=0.412$

Sargan test of overidentifying restrictions (Null: overidentifying restrictions are valid) chi2 $(59)=58.84$ Prob $>$ chi $2=0.481$ 